\title{
KEY ELEMENTS OF EVALUATION FRAMEWORKS FOR TRANSFORMATIVE R\&I PROGRAMMES IN EUROPE
}

\author{
MICHAEL DINGES, SUSANNE MEYER AND CHRISTOPH BRODNIK \\ DOI: 10.22163/fteval.2020.489
}

\section{INTRODUCTION}

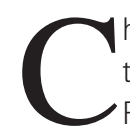

hallenges in climate, urbanisation and demography call for a transformation of societies and way of life. The von der Leyen's Political Guidelines assign Europe as leader of the transition "to a healthy planet and a new digital world. But it can only do so by bringing people together and upgrading our unique social market economy to fit today's new ambitions" (von der Leyen 2019).

Many governments, as well as the European Union (EU), have already responded by making changes to their research and innovation (RCI) policies shifting from merely stimulating technology development for the sake of economic growth to a system-oriented public Ryl policy that should bring about transformative change with the goal of adressing grand societal challenges (e.g. Missions and planned partnerships of Horizon Europe, Swedish Viable Cities Programme, JPI Urban Europe, EIT Climate KIC, etc.). It is acknowledged that R\&I policies contribute in coordination with sector, market or implementation policies to effective transformation.

The aspirations of the emerging Ryl programmes are high, and demand exists that these new programmes help to mobilise R\&I to address transformation challenges more effectively. However, past experience shows that it is not sufficient to support and finance "innovations" in order to achieve necessary structural change that the afore mentioned challenges demand. To accelerate system transformations hindering structures need to be dismantled. Transformation processes need to be politically designed and coordinated, in order to allow for a balance of conflicting societal interests (SRU 2016) and in parallel also a change of economic structures and associated societal implications has to be tackled, such as in the case of the transition towards electric-mobility or the phase out of a fossil fueld based energy system (SRU 2015).

Transformative R\&l programmes also require experimentation with a mix of instruments. For example, challenge oriented R\&l funding, new types of research and innovation actions with new types of stakeholders involved or even in the lead, change in regulation regimes, career incentives, living laboratories or public-private funding models, just to name a few. Challenges in the implementation of transformative R\&l programmes are manifold and the demand for learning and studying the effectiveness of such measures is high. Yet, it is unclear how such evalu- ation frameworks should be structured or what elements they should entail. Against this background, we discuss the implications for the evaluation of this type of emerging transformative R\&l programmes. Our key research question is:

What are key elements of evaluation frameworks for transformative R\&I programmes in Europe, which aspire to contribute to solve socio-economic challenges and spur transformation?

The focal point is on the relevance of Strategic Research and Innovation Agendas (SRIAs) and the Monitoring and Evaluation (MGE) systems that need to be set up following such an approach.

From an analytical point of view, we base our analysis on the nexus of shifting intervention rationales for public R\&l policies and the requirements for conducting theory-based evaluations and contribution analysis (Mayne 2008, Mayne 2011). We do this by analysing the changing nature of European Ryl policy making and contextualise these with existing evaluation paradigms. This analysis is based upon a literature review.

Empirically, we base our analysis upon an exemplary review of recent and emerging European Ryl policy initiatives, that pursue a transformative approach as they aim at shaping technological and societal change and contain transformative characteristics such as directionality, whole of governance approach, experimentation and multidisciplinarity, and co-creation, learning and societal engagement (see European Commission 2020, Schot and Steinmüller 2018). The analysis is based on the planned European Partnerships in Horizon Europe and the specific Joint Programming Initiative JPI Urban Europe. More specifically, we provide an overview, how Strategic Research and Innovation Agendas (SRIAs) of European Partnerships and evaluation logic models can be utilised as a starting point for the monitoring and evaluation (M\&E) of transformative R\&I policy. SRIAs encapsulates important elements of a transformative innovation policy approach as they are clearly challenge oriented, recognise the importance of engaging and coordinating a variety of stakeholders and draw on instruments outside the traditional realm of R\&I policy. 


\section{CHANGES IN EUROPEAN, TRANSNATIONAL AND NATIONAL RGI POLICY MAKING}

At the EU level and in many EU Member States, R\&I policies are increasingly geared towards contributing to tackling grand societal challenges by means of different programmes and instruments.

At the EU level, the new European Framework Programme for Ryl, Horizon Europe, aims at jointly tackling "Global Challenges and European Industrial Competitiveness" in its second pillar ${ }^{1}$. In addition, Horizon Europe incorporates new "RYI Missions" to increase the effectiveness of funding by pursuing clearly defined targets. Among other objectives, the missions shall link activities across different disciplines and different types of research and innovation and drive a systemic change and transform landscapes rather than fix problems in existing ones. Adding to that, a full roll-out of the European Innovation Council in Horizon Europe aims at putting Europe on top of the next wave of breakthrough and disruptive innovation that creates new markets, in particular by combining physical and digital products and services based on new technologies and business models.

Significant changes in Horizon Europe compared to Horizon 2020 are 1) a joint tackling of societal challenges and competitiveness, 2) a mission oriented approach towards R\&l policy making, and 3) an emphasis of creating new markets. These elements strengthen an orientation towards societal change and transformation. Although Horizon 2020 worked into this direction already, it turned out that the gap between highly abstract challenges and the reality of specific projects was very wide (Weber et al. 2019). By large, Horizon 2020 continued to pursue a technology centred approach in its second pillar, 'Industrial Leadership', while only the third pillar 'Societal Challenges', promoted integrated projects which were expressively not structured according to technologies but challenges that need to be resolved.

At the level of transnational networks of European countries, the European Partnership programmes will be strengthened in Horizon Europe to coordinate, pool and increase resources from Member States, research and industry to accelerate change across Europe and contribute to the Sustainable Development Goals. The European Partnerships are in the midst of preparing their re-configuration by the development of challenge and mission oriented Strategic Research and Innovation Agendas. Under the framework of the European Institute of Technology (EIT), the EIT Climate Knowledge and Innovation Community is another prominent example aiming to achieve system transformation through innovation (Brodnik et al. 2020), defining its purpose and mandate broad and positioning itself as a cross-sectoral initiative that goes beyond matters of innovation policy in a strictly economic sense (Diercks, 2018).

Many national governments have responded by making changes in part of their Ryl policies shifting from stimulating technology development and economic growth towards a more system-oriented public R\&l policy, at least in its objectives: they are gradually moving in this direction by introducing integrated and co-ordinated mechanisms with ambitious objectives in mind. Among others, examples for this can be found in Germany, in the field of renewable energies, following its decision to abandon nuclear power which is being accompanied with increasing efforts for Ryl funding for the transformation of the energy sector; the Netherlands, as seen in its current policy reform regarding top sectors; and of Japan, as reflected in its inter-ministerial research and innovation programmes (Cross-ministerial Strategic Innovation Promotion Program) (Larrue 2019).

\section{NEW LEGITIMATION OF PUBLIC RYI POLICIES AND NEW EVALUATION PARADIGMS}

The focus of European R\&I policy interventions has been moving from a 'project - instrument driven supply policy' to a more 'challenge driven, mission-oriented policy' approach, that can be characterised as follows:

- on the overall policy level, technological challenges and ambitions are being increasingly complemented (or even replaced) by an orientation towards addressing major societal challenges;

- on the instrumentation level, financial Rql instruments are combined with more demand side instruments, regulatory policy instruments, and sectoral policies, which altogether are sought to be orchestrated and complement each other;

- on a project level Ryl actors and problem owners increasingly share responsibilities for shaping and co-creating solutions that go beyond product and service innovations; target oriented R\&l portfolios rather than single-project-logics emerge.

These changes in the programming portfolio are triggered by a paradigm change in (European) R\&l policy making. Prevailing paradigms of R\&I policy intervention are based upon 1) rationales of market failures and funding modes for pre-competitive research, which contributed to the institutionalisation of public RYl support in the post World War II area, and 2) system failures - with the notion of National Innovation Systems and a focus on (missing) links and knowledge transfer between actors, networks and organisational learning. Transformative R\&I programmes add legitimation of public interventions in Ryl through 3) a transformation failure rationale in society (see Schot and Steinmüller 2018).

From the perspective of the market failure rationale, R\&I policy is legitimized only through a requirement to fix under-investment in $\mathrm{R} \& \mathrm{D}$ (which would lead to sub-optimal innovation output) and compensate for externalities (e.g. by e.g. by introducing IP-rights to incentivize private sector R\&D), which would ultimately limit the ability to commercialise scientific results and hamper economic growth (Weber \& Rohracher, 2012). The EU summits at Lisbon (2000) and Barcelona (2002) emphasized the importance and the public role of R\&D for increasing the competitiveness of industries and have thus decided to increase the R\&D intensity in the EU from nearly $2 \%$ in 2000 to $3 \%$ of GDP by 2010 . This European target, which is still not reached in 2020, is a prominent example justified by the market failure rationale.

In evaluations, the market failure rationale is closely linked to the concepts of input and output additionality. Input and output additionality analyses study the leverage effects of public funding for R\&D in terms of private spending and technological performance. The effectiveness of 
the presumed intervention mechanism that public incentives increase R\&D engagement in the business sector and that such additional publicly induced R\&D activities lead to new products and processes improving Europe's technological performance (Czarnitzky and Hussinger 2018) is at the center of these evaluations. Evaluation studies focussing on input and output additionality are by large summative, ex post evaluations. While these evaluations are capable to analyse the effects of an intervention by means of counterfactual econometric and bibliometric analysis, they tell little about the mechanisms that turn an intervention into a success or failure and are of limited use for learning and adaptation.

From the perspective of the system failure rationale, the actual use of knowledge, rather than just the production of knowledge through science, moves to the fore. This emphasizes the interactions between different types of actors, in particular science and industry (cf. Schartinger et al. 2006). An important focal point for this perspective is how a constellation of different actors and the interactions between them can strengthen the absorption of innovation in everyday practices of businesses or end-users (Diercks et al., 2019).

The system failure rationale was characterised by the emergence of new Ryl policy instruments like competence center programmes, which sought to bridge the gap between knowledge production and research outputs of the public research system and the production of market driven and societally valuable solutions in the business community, i.e. contributing to an increase in the productivity of knowledge investments through spillovers (Arnold et al. 2004, TAFTIE 2016).

In evaluations, the system failure rationale is closely linked to the concept of 'behavioural additionality'. The concept of behavioural additionality tried to enlarge the traditional perspectives in evaluation methods based on 'input' and 'output' additionality and link them with the policy framework of the national innovation system (Clarysse et al. 2009, Larosse 2004). Behavioural additionality is considered as the core of an evolutionary / structuralist view which urges policy action to increase cognitive capacities of agents and/or to resolve exploration, exploitation, selection, system, and knowledge processing failures, rather than simply addressing market failures (Gök and Edler, 2012). The emergence of the concept of behavioural additionality was important - as it in fact expressed a 'catching-up' of policy and evaluation theory on already widely applied practices of policy makers to explicitly target behavioural changes in the design of policy instruments (ibid).

The focus on behavioural additionality emphasizes a resource-based view on the firm (Georghiou and Clarysse 2006) and the interactions with public research organisations and collaborators along the value chain. Evaluations of public Ryl policies increasingly focussed on the network structures that emerged through public interventions (for example the inclusion of new actors, their role in the networks etc.) and the capabilities acquired by the organisations.

In the new third frame, the transformation failure rationale, the focus of the intervention moves beyond the sphere of Ryl policy because solving grad societal challenges cannot be relegated to this policy field alone. The transformation-failure rationale links R\&l policy to contemporary social and environmental challenges such as the Sustainable Development Goals and calls for transformative change. One widely used way of conceptualising transformation is the socio-technical system's perspective. In this body of literature, transformational changes are conceptualised as changes to the supply and demand side in the dimensions Science and Technology, Policy and Governance, Market and Users, Industry Structure and Strategy (see Ghosh \& Schot, 2019). As such, transformative innovation policy adds something to the innovation policy space that was thus far crucially missing: a normative purpose and directionality that goes beyond the general focus on competitiveness, economic growth and fixing market and systems failures (Weber \& Rohracher, 2012). For becoming effective, transformative innovation policies require a mix of 1) policies for creating support for niche innovation and 2) policies for destabilising existing regimes (ibid.). Within this framework, it is understood that changes in socio-technical systems often emerge at the niche level (small, local), as alternative configurations, and move towards creating change in the regime - which represents highly stable and entrenched configurations of the existing rules, technologies and social elements, which guide the actions of actors within a system and create pathways in which incremental change and evolution takes place (Markard et al., 2012)

While core principles of transformation-oriented innovation policies have already been identified and investigated, academic literature and experiences in conducting evaluations of transformation-oriented RYI policies are rare. Larsen (2019) developed a framework, in which transformational failures are being connected with structural elements of innovation systems. Together, they provide a framework for identifying systemic challenges and also potential instruments for addressing them. The framing could also be used for the purpose of evaluating transformative policy mixes. For evaluations of transformative Ryl policies, Molas-Galart et al. (2020) postulate the following six key principles that evaluations of these policies should adhere to: 1) using a formative approach aiming at improving policy definition and implementation, 2) integration within policy design and implementation processes, 3) addressing different levels of policy intervention, from specific projects at niche and local level to complex policy interventions involving different programmes, 4) participation and open debate should be facilitated and conflicts of power, interest and perceptions should not be avoided, 5) methodological diversity, which adapts methods and techniques according to the context, and 6) adoption of a generic Theory of Change (ToC), which should be informed by transformative innovation theory to help distinguish the key dimensions of a policy experiment.

Compared with the other framings of Ryl policies and their evaluations, the focus of evaluations needs to move from individual actors (firms, research organisations) to socio-technical systems, and the specific role of the state in driving policy change through a mix of instruments that aim at the creation of niche innovations with transformative potentials and measures destabilizing existing regimes through provision of incentives, deliberate phase-outs or changes to framework conditions.

In terms of monitoring outcomes, not the performance of individual firms or research organisations is in the centre of attention, but for example a change in discourse (new shared vision, new ways of thinking), practical applications of new technologies, changing modes of policy making, and new business practices in an ecosystem come to the fore (cf. Kivima 2020). Focal points are the generation of structural and procedural preconditions for enabling transformative change.

In the following we show, through which transformation-oriented principles and mechanisms European Partnerships attempt to contribute to the realisation of transformative change. Therefore, we focus on the definition of Strategic R\&I Agendas (SRIAs), which are based on transformation challenges that are being reflected in joint visions. Based upon the example of the Joint Programming Initiative Urban Europe, we then show, how SRIAs also need to be utilized for the definition of a MqE framework. 


\section{EUROPEAN PARTNERSHIPS: TRANSFORMATION ORIENTED INTERMEDIARIES}

The development of European Ryl partnerships across Europe and across stakeholder groups has been facilitated by the European Commission and the EU Member States following the Lisbon strategy with the aim to develop the European Research Area (ERA): These partnerships were originally designed and have been further developed to overcome the fragmentation in the R\&l landscape, to avoid duplication of efforts, to address the economic crisis, competitiveness and innovation².

European RyI Partnerships take responsibility for the "orchestration" of a transformative innovation policy agenda, in which orchestration can be understood as a type of normatively directed mutual coordination between different elements (actors, resource flows, activities,) in an innovation system (cf. Brodnik et al. 2020 on the role of R\&I partnerships as intermediaries). In contrast to the traditional emphasis on centralised control, orchestration points to the importance of mutual actions and interactions as the basis of pro-active adjustments by a range of different actors or by dedicated intermediaries (Kuhlmann \& Rip, 2018).

Under Horizon Europe, the new European Framework Programme for Ryl (2021-2027), the ambition of European Partnerships - with the Member States and Associated Countries, the private sector, research organisation and civil society organisations as partners - is to deliver on global challenges and modernise industry.

As an Ryl programming approach, we characterise European Partnerships transformative, as they aim at enabling the shaping of trans- formative change for society, economy and environment. They focus Ryl efforts not only on the provision of technological innovation and new solutions, but also on the change of production and consumption systems, including mobility, energy production, food and agriculture and other resources throughout society and industry (Schot and Steinmueller, 2018) which differentiates them from other Ryl programmes.

Their scope of strategic activities (see Figure 1), renders them transformative, as they represent elements of 1) directionality, 2) a whole of governance approach, 3) experimentation and foresight, 4) co-creation, learning and societal engagement (cf. European Commission 2020) and 5) institutionalisation and embedding. Partnerships perform the following strategic actions:

- Visioning: European partnerships seek to enhance directionality of $R$ y actions through a definition of a joint vision going beyond the sphere of R\&l policy making and a definition of core challenges by programme owners. Prominent examples are the 10 Joint Programming Initiatives², which aim to pool national research efforts and tackle common European challenges like climate change, healthy ageing of citizens, challenges of urbanisation etc. more effectively. The Joint Programming Process was launched by a communication of the European Commission in $2008^{3}$, which emphasized the need for a new approach to cooperation between Member States in the field of research for tackling Europe's major societal challenges more effectively.

- Open Governance: tailored structures through alignment of national policy measures and stakeholder engagement. The governance structures of European partnerships seek to align EU Member State policies according to the needs of the challenge to be tackled. Different types of partnerships are characterised by different types of key actors in the governance structures of

Figure 1: European Partnerships: transformative intermediaries through agenda setting, policy co-ordination and new instruments

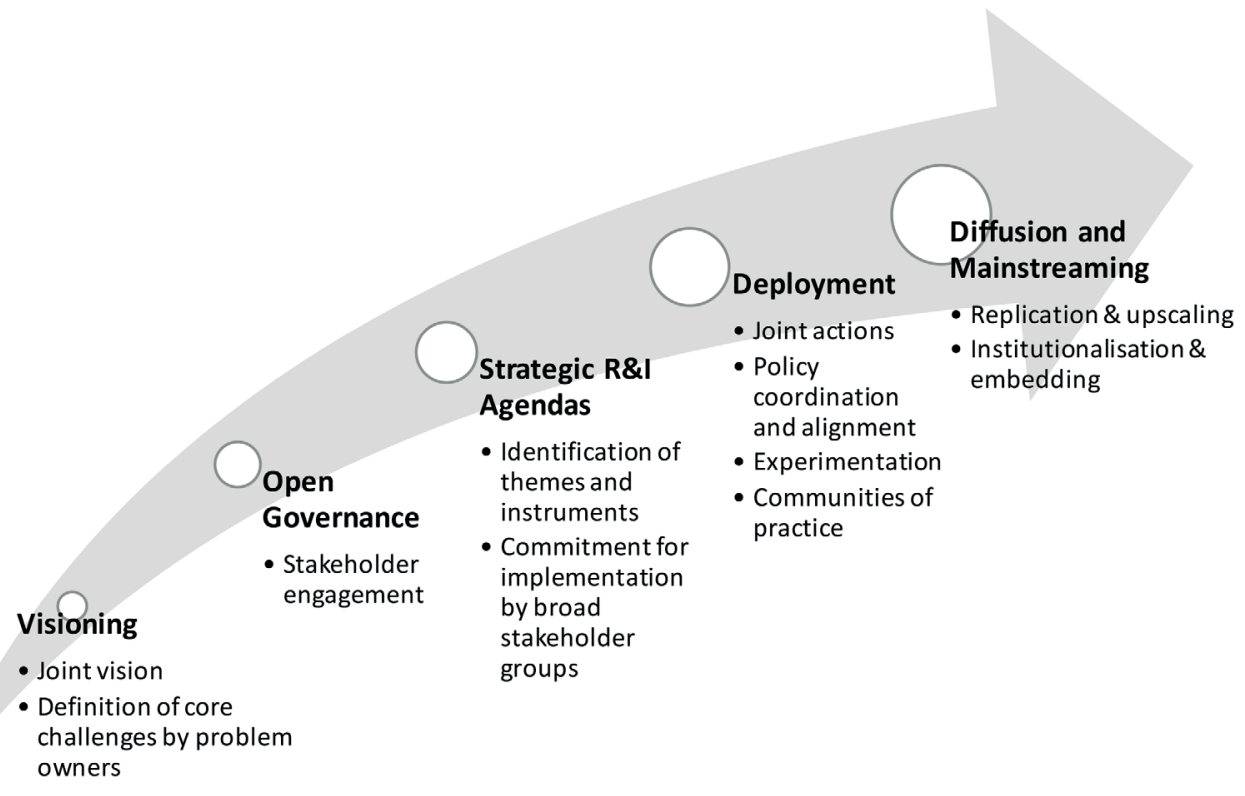

Source: Own illustration

2 See: https://www.era-learn.eu/partnerships-in-a-nutshell/european-partnerships/general-information

3 See: https://ec.europa.eu/programmes/horizon2020/en/h2020-section/joint-programming-initiatives

4 See: http://ec.europa.eu/research/press/2008/pdf/com_2008_468_en.pdf 
the partnerships and activities performed (Dinges 2019). In all stages of the joint programming process (from planning to deployment and diffusion), stakeholder engagement plays a key role in the governance of partnerships in order to ensure directionality of activities and enhance policy learning.

- Strategic RqI Agendas: translating a joint vision into an operational approach. SRIA is a partnership's strategy document, which identifies the partnership's targeted impact, foreseen portfolio of activities and measurable expected outcomes, resources, and milestones within a defined timeframe. As such, SRIAs do not only put emphasis on reaching a greater extent of directionality in R\&I actions, they try shaping a joint mindset among policy actors, R\&l actors and other stakeholders.

- Deployment: experimentation with multiple instruments. Experimentation in deployment instruments is another key feature of European Partnerships. The portfolio of instruments goes beyond Joint Calls for transnational research and innovation projects and includes Pan-European community building measures, creation of joint infrastructures, and actions for strategic alignment of national Ryl policies and operational alignment in research planning and implementation, guided by the priorities of the SRIAs are key elements of the partnerships instruments (cf. Meyer and Dinges 2017).

- Mainstreaming and diffusion: European Partnerships seek to create new configurations of Ryl and user communities and higher impact by deepening activities. Increasing the effectiveness of research and innovation through measures advancing the integration of innovations in existing institutional structures and measures for replication and upscaling are key ambitions of European partnerships.

The development of a SRIA constitutes a core element of all European Partnerships under Horizon Europe in order to ensure that their long-term vision is translated into concrete roadmaps with smart and measurable objectives. In the European Partnership landscape, SRIAs with a transformation orientation have been first developed by the Joint Programming Initiatives. In Horizon Europe SRIAs aim to ensure that European Partnerships pursue a systemic approach, driving transformative change through adherence to the following principles5:

1. Large-scale directionality and impact orientation: A SRIA should be developed with a main pathway to impact in mind and should allow to develop more practical action plans, in the form of a roadmap or an annual work plan, which are then set out accordingly.

2. Flexibility in implementation and activities beyond joint calls: A SRIA should foresee some flexibility in its modes of implementation, i.e. the SRIA is not an action plan. The SRIA should serve to give guidance without pre-determining specific actions in order to be able to take into account changing environments and to adjust to changing policy, societal and/or market needs, or scientific advance.
3. Synergies and complementarities between related activities at EU, national and regional level: A key element of a partnership's systemic approach is its contextualization. The contextualization of a partnership is an important element in the SRIA development process, where the analysis of R\&l trends and drivers, gaps and opportunities, national and European policy goals, and complementary activities and initiatives typically lay the framework for the partnership's expected R\&I contribution.

4. Mission driven and Challenge-orientated: A SRIA should include a mission and R\&l challenges ahead to reach the mission. The Ryl challenges should be elaborated by problem owners to reach a better demand articulation in the SRIA. The SRIA lay out means by which stakeholders have been addressed and engaged in the development process of the SRIA and will be throughout the operation of the partnership.

5. Anticipating changing needs and enhanced capacity to adapt/steer Rql strategies to those needs: In order to be able to anticipate changing needs and steer accordingly, a SRIA should include appropriate approaches for monitoring and assessing progress towards its strategic objectives.

In the development process, SRIAs should make use of forwardlooking methods (e.g participatory foresight, forecasts, visioning, as part of the agenda setting). They should also be co-designed and committed to by all partners and therefore involve a broad set of stakeholders early on in a participatory and co-creative manner. Views and opinions from relevant stakeholders such as member states, partners, R\&I actors and communities must be collected and appropriately fed into the SRIA in a way that it engages and empowers relevant stakeholders that they seriously commit to implement the SRIA with its activities and resources. ${ }^{6}$

In its results, SRIAs should not only define priorities that are being translated into general and specific objectives, and concrete actions, but they aim to provide a logic framework going beyond the development of technological solutions, building a holistic programming approach to support transformational change through, 1) a joint vision that unites the various stakeholders, 2) mobilisation of resources from different (policy) actors at different levels and EU Member States for realising the desired change, and 3) support for the emergence of new socio-technical regimes through creation of new solutions, practices etc. (niche building) and instruments that change existing regimes (e.g. through funding rules and instruments, R\&l and sectoral policy coordination related to a challenge, standards for stakeholder involvement). Hence, for European R\&l Partnerships SRIAs constitute a promising approach of transformative policy making, as they delineate both ambition and means for a missionoriented approach aiming to create landscapes rather than purely fixing markets (cf. Mazzucato, 2019).

In the following, we outline how the conceptualisation of monitoring and evaluation for European Partnerships relates to the conceptualisation of a SRIAs, which is in its essence a theory of change of a desired transformation process. For this purpose, we use the example of the monitoring and evaluation concept of the Joint Programming Initiative Urban Europe (Meyer et al. 2017).

5 See: https://www.era-learn.eu/support-for-partnerships/additional-activities/strategic-research-and-innovation-agendas/systemic-approach-form\#whyshould-sria-pursue-a-systemic-approach----which-principles-should-be-considered-when-establishing-a-sria-

$6 \quad$ For examples of SRIA development processes see: https://www.era-learn.eu/support-for-partnerships/additional-activities/strategic-research-and-innovation-agendas/guide-for-the-sria-development-process 
INTERVENTION LOGICS AND MONITORING OF TRANSFORMATIONORIENTED RYI POLICIES: THE CASE OF THE JOINT PROGRAMMING INITIATIVE URBAN EUROPE (JPI UE)

As a transnational R\&I programming initiative of 20 European countries, JPI UE follows a SRIA which provides the basis for devising the main activities and decisions of the initiative. The first SRIA was implemented from 2015 to 2020 and the SRIA 2.0 sets the main objectives from 2020 until 2026 (JPI Urban Europe 2015, JPI Urban Europe 2019).

Against the background of the SRIA, the management authority of JPI UE led the development process of a monitoring and evaluation concept (Meyer et al. 2017), which serves different purposes and actors.

\section{ACTORS AND PURPOSES FOR MONITORING AND EVALUATION (M\&E) IN EUROPEAN PARTNERSHIPS}

A dedicated and permanent M\&E system enables the management to 1) effectively steer and make decisions in the partnership, 2) adjust and fine-tune joint actions and 3) measure progress towards outcomes and impacts. Additionally, it allows for fast-track reactions, analysis and requests from the Steering Body of the partnership, the European Commission (EC) and the High Level Group for Joint Programming (GPC).

In its present form under Horizon 2020, actions related to MGE of European Partnerships are being performed by a number of different entities including in particular the management authorities of partnerships, the European Commission, and in the case of Public-Public-Partnerships the High Level Group for Joint Programming (GPC):

- The managing authorities of European Partnerships are intermediary institutions, which are responsible for the implementation of the partnership SRIA. The managing authorities are responsible for designing and applying a partnership specific monitoring and evaluation system for internal steering and decision making. In the case of the Joint Programming Initiative Urban Europe, the managing authority consists of experts that are delegated by national and regional owners and managers of Ryl programmes that participate in JPI Urban Europe. The managing authorities are primarily responsible vis a vis the principal decision-making body. In the case of JPIs the decision making body consists of representatives of member states or associated countries whereas in the case of Public-Private Partnerships such as the Art. $187 \mathrm{JTI}$ they present the European Commission, European Industrial Associations and EU Member States.

- The GPC has established a working group to provide guidelines and suggestions for performance measurement across all JPIs (GPC Working Group „Measuring JPIs' Progress and Impact” and GPC Implementation Group on "Monitoring \& Evaluating JPIs").

- The EC regularly evaluates the process to ensure that that the objectives and impacts of each partnership are in line with the objectives of the overall process and thus contributing to overarching policy goal. In the case of the Joint Programming independent expert reviews (Acheson et al. 2012, Hunter et al. 2016) reported on the successes and failures of the process. As the European Commission is the main co-funder of European Partnerships, the Management Authorities of the Partnerships are also responsible to report to the $\mathrm{EC}$ on the effectiveness and impact of the Initiative.

- Furthermore, the European Commission has funded the ERALEARN project, which aims to support the JPIs with expert advice and has provided a short "Guide on P2P evaluation / impact assessment" (Amanatidou et al. 2016) and a number of national and field specific impact assessment reports on various partnerships?.

Compared with other policy initiatives we notice that monitoring and evaluation activities of European Partnershisp are embedded in a multilevel system in which the managing authorities are not only responsible for the process of setting targets, but also take over responsibilities regarding the operational side of monitoring and evaluation.

Striking the balance between "internal learning needs" and provision of "external legitimation" are inherent challenges for the European Partnerships in this regard. Key pre-requisites therefore are: 1) developing an appropriate M\&E system in which objectives and pathways for achieving impact are accurately framed upfront and 2) shared responsibilities for $\mathrm{MGE}$, in which the managing authorities of partnerships put a strong emphasis on learning through means of monitoring and self-evaluation while external institutions account responsible for the evaluation of the overall effectivness.

In the follwing we show how the Joint Programming Initative Urban Europe (JPI UE) has operationalised its M\&E system based upon the SRIA. JPI UE makes use of a logic framework, which aims at capturing the transformative ambition of the initiative.

\section{A LOGIC MODEL DELINEATING MULTIPLE PATHWAYS TO IMPACT}

One of the most useful tools for enabling monitoring and evaluation of a public policy intervention or programme is the development of a logic model, which represents the programme theory (cf. Amanatidou et al., 2016 in the context of European Partnerships). A logic model outlines the connection between ends and means of a programme. It comprises 
the underlying rationales of a programme (a specific challenge to be addressed), formulates specific objectives that should be achieved by the programme, and provides an overall roadmap on how specific activities of the programme can be expected to produce immediate outputs connected to outcomes/intermediate impacts and eventually the realisation of the objectives (the long-term impacts).

Thereby, a specific challenge of transformation oriented R\&I initiatives is to establish causal linkages between challenges going beyond the R\&I sphere, its activities, outputs, outcomes and impacts. Although we can establish logical links between them, measuring this is difficult due to attribution problems, particularly in complex research environments as they are addressed in JPIs. For setting up a logic model it is important to first revisit the rationale for the JPI. Generic logic models are made up of the following steps:

1. An analysis of the challenges, needs or issues that need policy intervention, assuming that markets and other social processes will not lead to sufficient improvements. These challenges are translated into rationales or reasons for policy intervention. For existing JPIs a first step is to revisit the rationale for the JPIs i.e. to consider all reasons for which the JPI was established, and the problems, situation or challenges it aims to tackle.

2. This analysis of problems and associated policy reasons implies a set of objectives, with the aim to address and ideally solve the defined (societal) problems.

3. In turn, this leads to the main instruments/measures/joint actions that are undertaken to best address these objectives, which need input, typically time and human and financial resources, although political and infrastructural preconditions may also have to be met. The inputs enable activities that are expected to lead to outputs. The use of these outputs by the target group leads to the immediate results of the work enabled by the inputs.
4. The outputs enable wider results or outcomes to be created. It is expected that the outcome of JPIs primarily affect the change of behaviour of the direct beneficiaries of the R\&l activity. In this sense, the society as a whole has not yet received a payback on its investments.

5. The results or outcomes enable wider (economic or societal) impacts that also affect society at large or enable system change and contribute to the tackling of a societal challenge.

JPI UE follows three different types of objectives which place the JPI and its existing activities in a policy context of: 1) urban policy and urban society objectives, 2) urban R\&I objectives and 3) R\&I policy and governance objectives. JPI UE objectives that address urban policy and society relate to the ambitions of the Sustainable Development Goals and the EU Urban Agenda. It also reflects where the JPI UE aims to make an impact by its R\&I (stimulate better urban policies and better urban societies) JPI UE objectives that address urban R\&I and the respective R\&I policy and governance derive from the general ambitions of the JPI Process (European Commission, 2008), which outlines that JPIs aim to respond to societal challenges through targeted research and innovation strategies, programmes and activities (RYI Objective) and to better coordination and integration of national R\&l policies and programmes (R\&I Policy and Governance Objective).

Based on the challenges and rationales for joint programming in the field of urban development, a number of long-term strategic objectives relating to the three policy contexts (Urban policies, urban R\&I, R\&I Policy and Governnace) with a target horizon of 2026 are articulated for JPI Urban Europe in its strategy. The objectives set out were agreed among the participating Member States and provide the frame for the next development phase.

Figure 2 exemplifies that M\&E activities of the JPI Urban Europe need to focus not only on Rql objectives, but have to put emphasis on:

Figure 2: JPI UE contributions by overarching policy objectives and basic elements of the logic framework

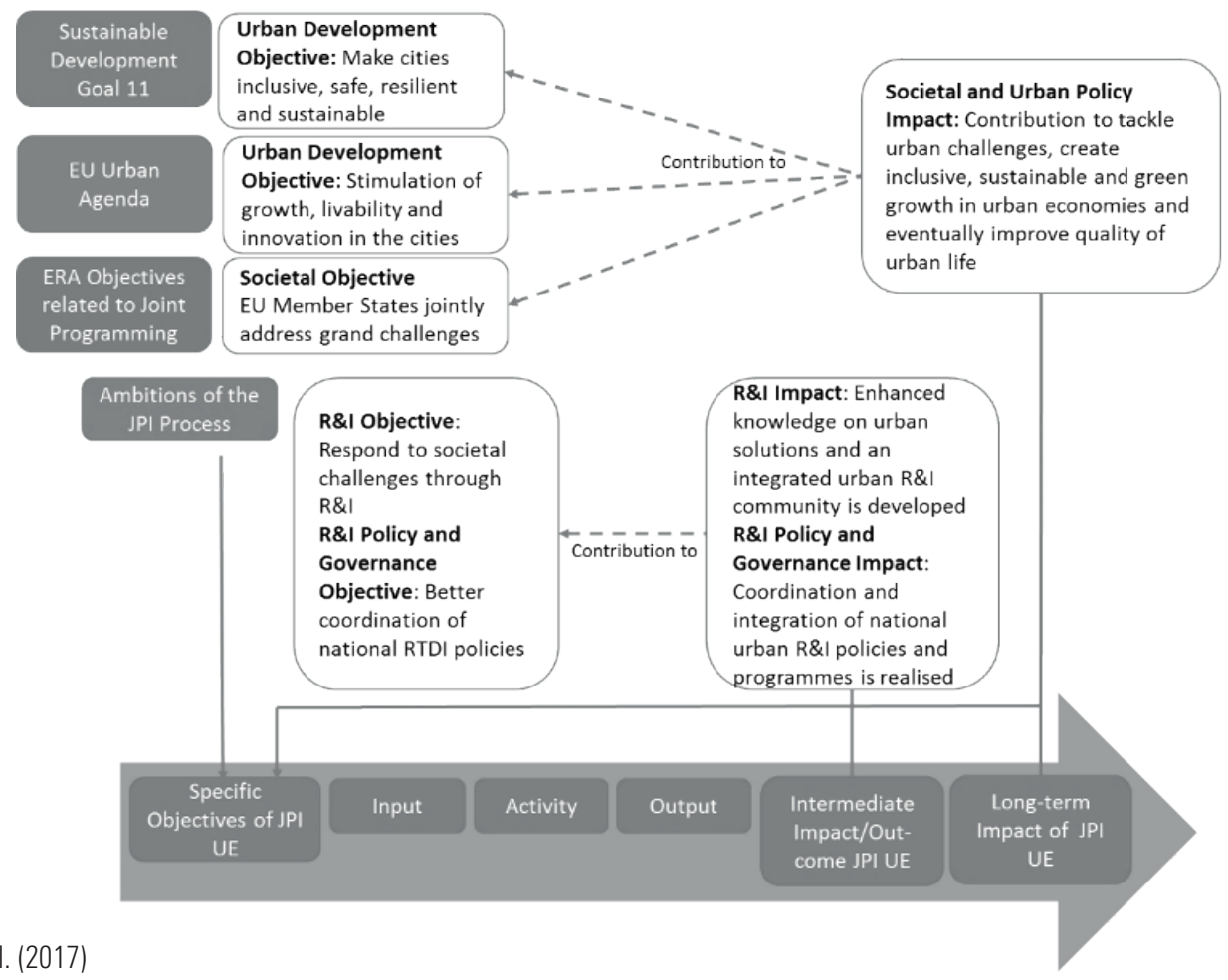


- the process of Rgl policy making including the experimental development of new instruments,

- the governance of the response to the challenge in an overarching policy making context (through coordination of national policies), and

- its influence on the system level (urban development) through its portfolio of actions that focus on the creation of a transdisciplinary urban R\&I community and the provision, replication and upscaling of new urban solutions.

The long-term impacts of the JPI Urban Europe are expected to go beyond RYl, but enable system change of urban policies and societies as outlined in the SRIA of the JPI. This also corresponds to the expectations outlined in the ERA priorities. Additionally, these impacts should deliver to the ambitions of the Sustainable Development Goals and the EU Urban Agenda.

M\&E activities for transformative R\&I policy instruments therefore need to take a broader perspective than other R\&I programmes as they seek to deliberately and actively address and exert impact on a defined system level (in this case - liveably European Cities and their green and sustainable growth), which requires action on different levels through different means of actions.

This multi-level-perspective differentiates evaluations of European Partnerships from other R\&I policy initiatives, in which the core focus is predominantely on a portfolio of projects and the knowledge creation and knowledge transfer processes that are being stimulated by them.

\section{STRUCTURING M\&E ALONG OVERARCHING POLICY GOALS AND OPERATIONALISATION OF IMPACTS}

For structuring the M\&E acitivities, the three areas/domains of societal objectives, R\&l objectives and R\&l policy objectives provide a formal way of thinking about the initiative. In order to operationalise the strategic targets of the JPI Urban Europe in a first step 'operational objectives' to be reached have been defined as intermediate steps for approaching the strategic objectives. The operational objectives are more concrete and tangible than the strategic objectives. Secondly, these objectives were then linked to implmentation instruments.

As JPI Urban Europe pursues a number of interdependent objectives at different levels, the initiative makes use of a portfolio of 'instruments' to implement the SRIA in order to meet the objectives. These included at the time of the creation of the MGE system (1) transnational Joint Calls, (2) design and experimentation with new instruments for higher impact (e.g. innovation and alignment actions) (3) a Stakeholder Involvement Platform (SIP), (4) establishment of an effective programme management (PM), (5) Communications and Dissemination (C\&D), (6) Institutional Cooperations - Urban Europe Research Alliance (UERA), (7) the continous development of the Strategic Research and Innovation Agenda (SRIA) 2.0, and (8) governance mechanisms to widening participation. The instruments contribute to various strategic and operational objectives of the initiative, interact with each other and with other initiatives at European and national level (See Table 1).

Evaluations, which try to capture the outcomes and impacts of an intervention need to take into account the type of intervention, the targeted beneficiaries and the contexts in which the intervention takes place. Whereas outcomes and impacts of certain interventions like mobilisation of different actor groups and results from projects funded via calls might be measured quite accurately, the overall contribution of JPI UE to tackle urban challenges and contribute to inclusive, sustainable and green growth might only be traced once a coherent set of measures has been set up and is fully active. It also needs to be considered that there is a) non-linear cause-effect relationship, and b) that the long term socio-economic impact is also dependent upon many external factors.

The long-term impact of the initiative should become evident at the level of society and urban policies, as the JPI process has been established to ultimately tackle societal challenges. As indicated in Table 2, the outcomes or intermediate impacts of JPI Urban Europe are targeted to accrue at three different levels. Impacts reached on these levels can be considered as enabler and pre-condition for achieving the desired wider socio-economic impacts. 
Table 1: Instruments of JPI Urban Europe to implement the objectives Source: Meyer et al. (2017)

Instruments for implementation of objectives

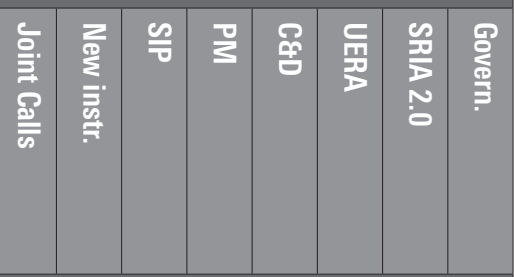

1. Societal and Urban Policy Objectives

Contribution to tackle urban challenges, create inclusive, sustainable and green growth in urban economies and eventually improve quality of urban life
1.1. Become a well-recognised source of evidencebased knowledge and integrated solutions for informing European and international urban policies

1.2. Foster public sector innovation and capacity building in urban planning, management, and (regional, national, EU, and international) policy making for urban transitions

1.3. JPI UE in all its activities mobilise societal actors and stakeholders to co-create ideas, concepts and solutions to better meet societal and cities' needs

1.4. Raise visibility of JPI UE in the various target groups, strengthen communication with public and private sector stakeholders and establish as an attractive partner for cities, business and societal actors to optimise and accelerate urban transitions

\section{R\&I Objectives}

Enhanced knowledge on solutions for the urban challenge are developed and an integrated urban R\&I community is built in Europe
2.1. Setting common research priorities according to the EU Urban Agenda and UN Sustainable Development Goals

2.2. Address and connect fragmented socio-technical approaches to sustainable urban solutions and enhance knowledge, research capacity and impact of research on urban transition

2.3. Within the strategic framework, being responsive to urgent urban issues by creating and promptly translating relevant knowledge and evidence

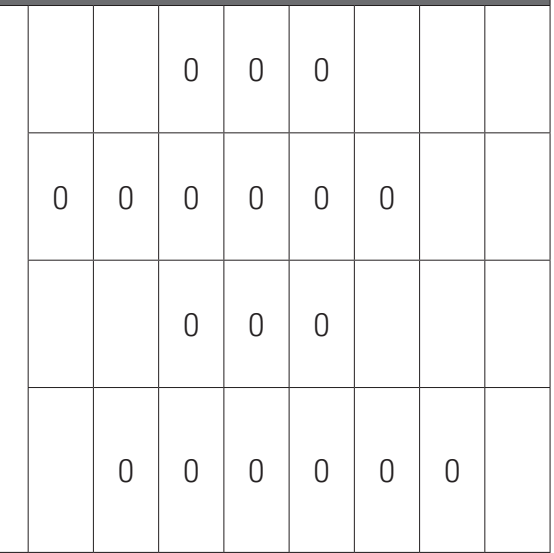

\section{R\&I Policy and Governance Objectives}

Coordination and integration of national

RGl policies, programmes and instruments in the urban area on transnational level
3.1. Align national R\&l programmes, priorities and activities to enhance competencies, improve the efficiency and increase mutual learning at the level of Member States and the European Research Area

3.2. Widen the portfolio of instruments for urban research and innovation to meet the set ambition and create a testbed for new approaches that are targeted towards co- creation, exploitation and innovation

3.3. Improve the governance system to maintain cooperation under variable geometry and allow easy access to the partnership for new actors and members

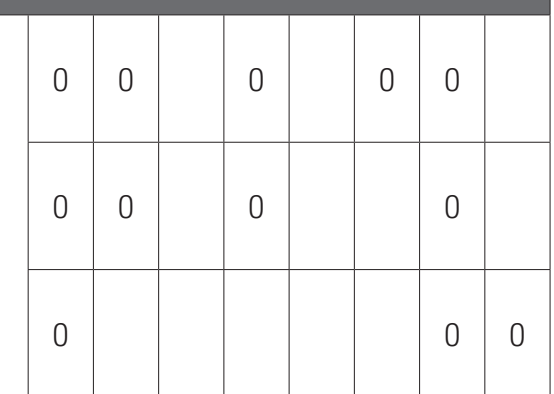


Table 2: Expected Impact of JPI Urban Europe

Source: Meyer et al. (2017)

\section{Expected Impact $\quad$ Operationalisation of conditional impacts}

\begin{tabular}{|c|c|c|c|c|}
\hline $\begin{array}{l}\text { Contribution to tackle } \\
\text { urban challenges, create } \\
\text { inclusive, sustainable } \\
\text { and green growth in } \\
\text { urban economies and } \\
\text { eventually improve } \\
\text { quality of urban life }\end{array}$ & $\begin{array}{l}\text { Urban solutions based } \\
\text { on JPI UE activities } \\
\text { have been implemented } \\
\text { and translated in } \\
\text { (European) cities. }\end{array}$ & $\begin{array}{l}\text { JPI UE in all its activities } \\
\text { mobilise societal actors } \\
\text { and stakeholders to co- } \\
\text { create ideas, concepts and } \\
\text { solutions to better meet } \\
\text { societal and cities' needs. }\end{array}$ & $\begin{array}{l}\text { JPI UE delivers } \\
\text { transnational good practice } \\
\text { guidance how to improve } \\
\text { urban sustainability } \\
\text { and quality of life. }\end{array}$ & $\begin{array}{l}\text { JPI UE is consulted } \\
\text { to shape regional, } \\
\text { national, European } \\
\text { and international } \\
\text { policies for sustainable } \\
\text { urban development. }\end{array}$ \\
\hline
\end{tabular}

2. R\&l Impact

Enhanced knowledge on solutions for the urban challenge are developed and an integrated urban R\&I community is built in Europe

\section{Mechanisms and tools} have been created that facilitate better circulation and application of urban knowledge and expertise for stakeholders at national, European and international level
Challenge driven RDI approaches (applying a inter- and transdisciplinary research, merging consistently 'excellence' with 'relevance') are 'standard' in many European countries

\section{R\&I Policy and Governance Impact}

\section{Coordination and} integration of national $R g$ policies, programmes and instruments in the urban area on transnational level
JPI UE delivers an increase in the number of European countries strategically aligning national policies, programmes and investments around the sustainable urbanisation challenge throughout the innovation system

\section{JPI UE has developed} and tested new Rgl instruments and framework conditions to tackle the diverse urban challenges and support scale up and exploitation of research results and solutions.
Taking the elaborated logic framework and operationalisation of impact as basis, the indicators of the monitoring and evaluation system of JPI Urban Europe were then designed to provide a comprehensive view of instruments, addressed types of objectives (R\&I, R\&I Policy and Governance, Societal and Urban), and measures over the impact cycle (i.e inputs, activities, outputs, outcome/impacts).

Structuring the impact of the Joint Programming process along three impact domains provided a formal way of thinking about the initiative and a tool for building a coherent set of indicators, which consider: 1) the instruments under consideration, 2) their implementation (inputs and activities) and desired results (outputs, outcomes and impacts), 3) tentative sources of information, 4) main stakeholder group being responsible for providing the information, 5) the desired frequency and format for measurement, and 6) the indicator's use for monitoring purposes or evaluation purposes.

For selecting the core set of indicators for JPI Urban Europe, the 'RACER' criteria were applied. RACER stands for relevant, accepted, credible, easy and robust and has been recommended by the European Commission in its Better Regulation Toolbox to assess and select indicators for use in policy making ${ }^{8}$.

Table 3 displays a selection of a limited number of outcome/impact indicators that have been tailored to the instrument and the strategic and operational objectives of the initiative. The outcome and impact indicators predominantely address Rgl Policy and Governance Objectives and Societal/Urban Policy Objectives rather than Rgl objectives. They refer to dimensions that underpin the transformative ambition of the initiative. These include impact on:

- Structuring the policy field for enabling transformation building a coherent European R\&I policy approach for sustainable cities: EU Member State commitments to pursue a joint transformative research and innovation agenda is a key ambition of the initiative. Participating EU Member States start to change existing, sectoral oriented regimes of R\&I programmes towards the ambitions outlined in the SRIA of JPI UE. Sectoral energy 
and mobility programmes are changing their set-up towards trans-disciplinary, integrative approaches. This is measured by an (annual) analysis of the number (and volume) of Member State programmes that relate/correspond to the JPI UE strategies and approaches as defined in the SRIA on the national level (Indicator No. 4), and the extent to which collected information provided by JPI UE is used for practical work of major policy stakeholder groups such as national ministries, funding agencies, and cities (No. 23). For further complementing this type of impact, also the consideration of JPI UE strategies outside the Ryl policy domain and collaborations with related policy fields would shed light on the outreach of structural impact.

- Capacity building for transdisciplinary R\&l and user communities: strengthening of knowledge transfer within the new configurated innovation communities (№. 11); creation and use of european research infrastructures and data on urban matters
(No 17, ) and positioning of the initiative as a knowledge hub for urban solutions, well-known to the stakeholders (№. 18) are examples in this regard.

- Creating niches and replicate and upscale urban solutions : In the SRIA of JPI UE research questions are framed along core dilemmas of users/problem owners rather than technological development tasks. The creation of novel solutions and practices are at the core of the R\&I practices of JPI UE. The novelty and sustainability of collaborations between different types of RYI organisations and end-users, joint engagment in market activities (№. 9) and number and type of urban solutions that have been upscaled and replicated (No. 11) are indicators which refer to the ability to create niches and foster transformation through upscaling.

Table 3: Selection of Outcome/Impact indicators for M\&E of JPI UE ${ }^{9}$

\begin{tabular}{|c|c|c|c|c|}
\hline No & Instrument & Indicators & Strategic Objective & $\begin{array}{l}\text { Operational } \\
\text { Objective }\end{array}$ \\
\hline 4 & Alignment & $\begin{array}{l}\text { \# of JPI UE MS programmes that relate / correspond to JPI UE strategies } \\
\text { and approaches on the national level } \\
\text { (clear definition needed to delineate relevant national R\&I programmes) }\end{array}$ & $\begin{array}{l}\text { RGI Policy and } \\
\text { Governance Objectives }\end{array}$ & 2.2 \\
\hline 9 & Joint Call & $\begin{array}{l}\text { Share of projects that have engaged in follow up activities: } \\
\text { - sustainability of collaborations of enterprises or research organisations } \\
\text { with end-users in research, development, and piloting activities } \\
\text { - sustainability of collaborations of R\&l partners that are collaborating } \\
\text { after the end of the project } \\
\text { - Engagement in joint market activities for urban solutions }\end{array}$ & $\begin{array}{l}\text { Societal and Urban } \\
\text { Policy Objectives }\end{array}$ & 1.4 \\
\hline 11 & Joint Call & $\begin{array}{l}\text { Capacity Building: Follow-up project activities exists } \\
\text { to strengthen knowledge transfer and cooperation } \\
\text { between differnt types of project partners }\end{array}$ & $\begin{array}{l}\text { R\&I Policy and } \\
\text { Governance Objectives }\end{array}$ & 3.1 \\
\hline 10 & Joint Call & $\begin{array}{l}\text { \# and type of urban solutions that have been upscaled } \\
\text { and replicated during or after project funding }\end{array}$ & $\begin{array}{l}\text { RGI Policy and } \\
\text { Governance Objectives }\end{array}$ & 3.2 \\
\hline 17 & UERA & $\begin{array}{l}\text { European research infrastructure and data on urban matters is } \\
\text { connected/built and delivers new insights on urban development }\end{array}$ & $\begin{array}{l}\text { Societal and Urban } \\
\text { Policy Objectives }\end{array}$ & $1.3,2.2$ \\
\hline 18 & UERA & $\begin{array}{l}\text { JPI UE through all its activities is a knowledge hub for urban solutions } \\
\text { and well-known to the stakeholders when looking for urban solutions/ } \\
\text { well recognised network that influences decision making processes } \\
\text { at European level (e.g. operationalised via stakeholder surveys, } \\
\text { representation of UERA members in decision making bodies...) }\end{array}$ & RgI Objectives & 2.3 \\
\hline 23 & Strategy & $\begin{array}{l}\text { The extent to which collected information provided by JPI UE is used } \\
\text { for practical work of major stakeholder groups dealing with the issue } \\
\text { of sustainable urban development and transition (national ministries, } \\
\text { funding agencies, cities, business, researchers, civil society) }\end{array}$ & $\begin{array}{l}\text { Societal and Urban } \\
\text { Policy Objectives }\end{array}$ & 1.4 \\
\hline
\end{tabular}

Source: Meyer et al. (2017)

$9 \quad$ In 2018 a first pilot monitoring has been performed. Based on the pilot test, some indicators have been refined and made more concrete and applicable. Currently, the entire online monitoring system is being developed and tested, which enables JPI UE to also collect information on the indicators in due time. 


\section{DISCUSSION \& CONCLUSIONS}

The analysis of recent policy developments in the EU shows that European R\&I initiatives such as the European Partnerships are increasingly transformation oriented in their overall ambition. While R\&l policy evaluation has elaborated concepts that allow focussing on the analysis of the effectiveness of public subsidies for Ryl in terms of additionalities on inputs, outputs and behavioural characteristics, concepts for monitoring and evaluating the change of R\&I policies in a socio-technical-system perspective and the respective influence of $R \& l$ policies on these systems have yet to be developed.

The scope of strategic activities that is being performed by European Partnerships characterises them as transformation-oriented intermediaries. They play a key role for 1) designing Ryl policy processes through strategic policy coordination, 2) linking actors of different communities, and 3) providing room for experimentation and policy learning through the development of new instruments with a transformative agenda.

At the core of this agenda, the SRIAs resembles a complex, transformative theory of change, which translates a joint vision of a partnership into operational mechanisms that are supposed to deliver different types of impact. They change the policy discourse and provide new shared visions, new ways of thinking and a changing mode of policymaking with new actors involved. SRIAs are supposed to position actors of different communities around certain challenges, elaborate a joint and common understanding and new approaches towards solving societal challenges on the one hand, while also delineating potential frictions and conflict of interests among different types of stakeholders on the other hand. As such, Strategic Research and Innovation Agendas constitute an integral part of new, transformation-oriented R\&I policies.

In their ambition to build a narrative for transformational change, SRIAs take account of 1) influential factors that exert influence on outputs, outcomes and impacts and 2) different impact dimensions that link $\mathrm{RYI}$ and other policy objectives. As a main result of a strategic planning activity, SRIAs therefore provide a self-set baseline for evaluations and its pathway to impact, against which these initiatives should be evaluated against. Therefore, the quasi-linear approach of following inputs, activities outputs etc. needs to be overcome in evaluations of transformative Ryl policies, by focussing more closely on the role of the involved intermediaries within the socio-technical-system, the influential factors shaping the socio-technical system, and the different impact dimensions that are being targeted by the initiatives (see Figure 3).

The M\&E concept of the JPI UE shows that transformative evaluation frameworks need to put stronger emphasis on the linkages of 1) societal and sectoral policy objectives, with 2) R\&I objectives and 3) R\&I Policy and Governance Objectives. For combining them coherently in evaluation processess, also the different intervention mechanisms (instruments) within and outside the initiative, their interplay with each other, and the impact of influential factors on the outcomes/and impacts have to be scrutinised. In order to get a better understanding on the potential impact of these types of initiatives for driving transformational change, SRIAs and MGE activities would need to take a stronger focus on the external world and the required institutional and regime changes outside the R\&I policy domain. This comprises in particular interactions with sectoral top-down oriented policies that actually exhibit a huge impact on the speed of transformation. So far, both SRIAs and M\&E systems of partnerships seem to put too little emphasis on these aspects.

The analysis further demonstrates that the intermediation activities of the initiative are framed by a vision and mission that provides a transformative direction to its activities, i.e. to support urban transitions by supporting knowledge creation, setting common priorities, aligning R\&l instruments, moderation of science-policy processes and the support of transnational collaboration as well as local capacity building. Against this background it is evident, that transformative R\&l policy evaluations need to take a particular strong focus at the governance mechanisms of the challenge oriented approach and the ability to exert impact on policy making processes. Transformation oriented R\&I initiatives seek to steer

Figure 3: From linear intervention logics to impact pathways Source: Own illustration

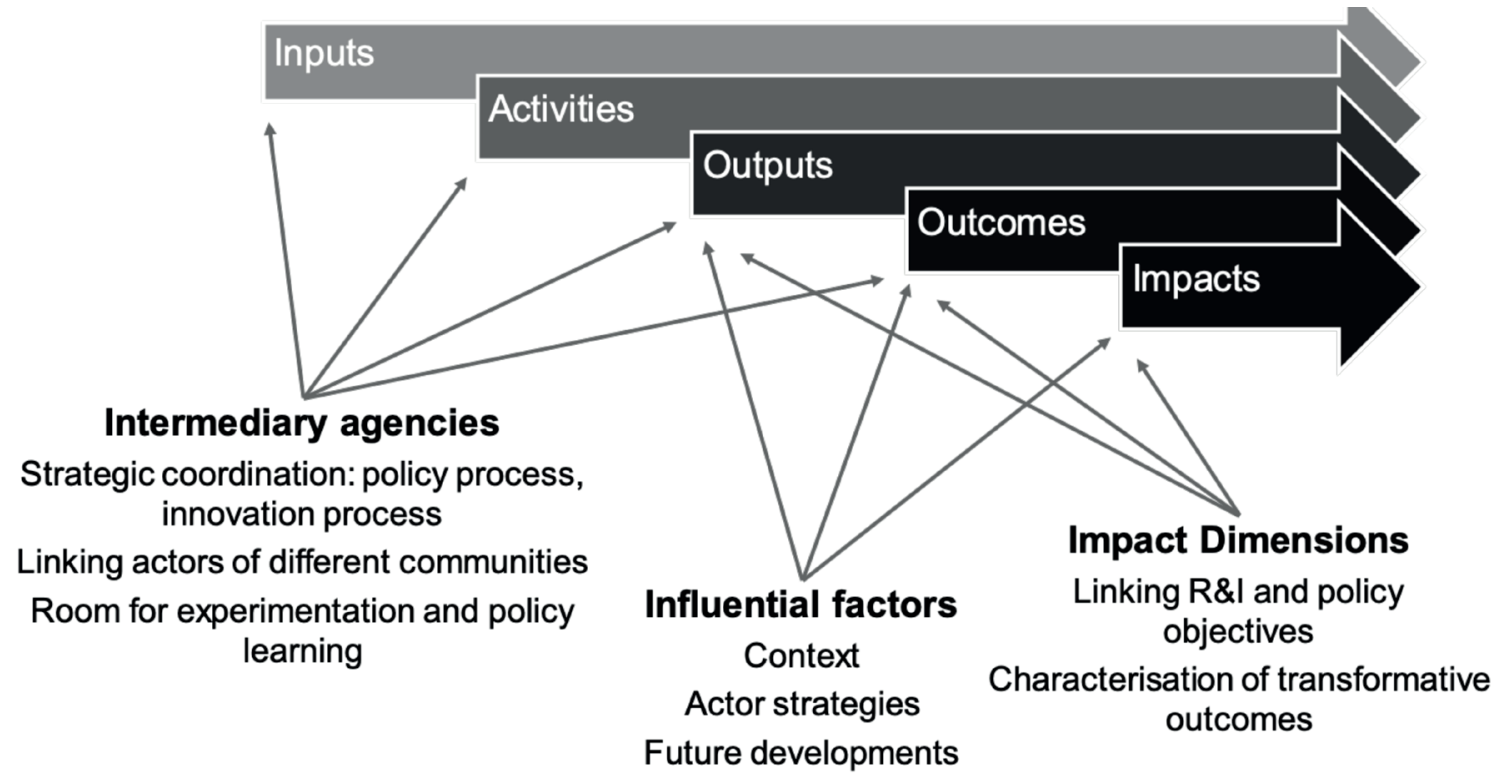


policy processes in a certain direction and exhibit structural impact on different levels of policy making. Therefore, the role of the intermediary initative for facilitating change, and its capacity to steer the policy process as well as the influental factors that have intended/unintended impact on the interventions have to come to the fore of transformative evaluations .

From an Ryl perspective, 1) network formation and capacity building for transdisciplinary R\&I and user communities and 2) the ability to create, replicate, upscale and 3 ) institutionalise and embedd novel solutions in industry sectors are additional elements that transformative Rgl evaluations need to focus on. Capacity building elements include the sustainable formation of new networks of R\&I actors, policy makers at different levels, and users - as well as the creation of jointly used knowledge, data and infrastructures. In our example of JPI UE this is being enabled through specific stakeholder dialogues, strategic partnerships, joint investments in urban Rql, urban living labs, and project portfolio management activitities. The ability to create, replicate and upscale novel solutions is a key ambition of RqI activities enabled by JPI UE. For enabling replication and upscaling, networks do not only need to form - but reflexice learning processes need to accrue among the network members. Therefore, transformative evaluations do not only need to analyse aspects of network growth and diversity, but also on the ability of involved actors to take up novel concepts/solutions/practices to other locations or contexts and link it to other initiatives.

Our analysis further shows that the managing authorities do not only have an important role to say in the development process of the initiative, but also as regards the design and implementation of the MqE system itself. In transformative R\&I policies, the boundaries between the learning functions of evaluation activities, and the legitimation function of assessements become increasingly blurred. The intermediary managing agencies are by large being held responsible for 1) developing complex intervention mechanisms, 2) facilitating policy-learning across the members of the partnerships, and 3) demonstrating accountability. Obviously, this inherently creates tensions and conflicts of interests, which can only be overcome if internal self-assessment activities and external evaluations play well-defined complementary roles in the evaluation process.

\section{REFERENCES}

Acheson, H.; Annerberg, R.; Dammert, R.; Klusacek, K.; Kraus, W.; Lock, J. (2012): Review of the Joint Programming Process - Final Report of the Expert Group. https://era.gv.at/object/document/1190

Amanatidou, E., Cunningham, P., Cox, D., Hunter, A., Dinges, M., Köngeter, A., Meyer, S. (2016), Guide for P2P Impact Assessment, ERA-LEARN 2020. https://repository.fteval.at/367/1/ERA-LEARN\%20 2020\%20D3.4a\%20Guide\%20revision_DEC2016_final.pdf

Arnold, E., Deuten, J., and van Giessel, J. F. (2004). An international review of Competence Centre Programmes. Brighton: Technopolis Group.

Brodnik, C., Kalcik, R., Meyer, S., Weber, M., Matti, C. (2020). The Role of R\&I Initiatives in Transformative Change Processes: The Case of EIT Climate KIC and JPI Urban Europe. 11th International Sustainability Transitions Conference 2020 (IST2020): Governance in an Era of Change - Making Sustainability Transitions Happen, Vienna.
Czarnitzki, D. and Hussinger, K. (2018). Input and output additionality of R\&D subsidies. Applied Economics, 50(12), 1324-1341.

Clarysse, B., Wright, M. and Mustar, P. (2009). Behavioural additionality of R\&D subsidies: A learning perspective. Research Policy, 38(10), 1517-1533.

Diercks, G. (2018). Transformative Innovation Policy. Imperial College London.

Diercks, G., Larsen, H., \& Steward, F. (2019). Transformative innovation policy: Addressing variety in an emerging policy paradigm. Research Policy, 48(4), 880-894.

Dinges, M. (2019), Synthesis Report on the Partnership Landscape in view of the clusters in Horizon Europe, ERA-LEARN Discussion Report. https://www.era-learn.eu/documents/thematic_analysis_synthesis_report.pdf.

ERA-LEARN 2020 (2016a): Background document on P2P evaluation / impact assessment, Deliverable D3.4b. https://www.era-learn.eu/ monitoring-and-assessment/Monitoring-and-impact-assessment-ofnetworks/ERALEARN2020D3.4bBackgroundDocumentfortheP2PIAGuide prefinal.pdf

ERA-LEARN 2020 (2016b): Short guide on P2P evaluation / impact assessment. Deliverable D 3.4a. https://www.era-learn.eu/publications/ other-publications/guide-for-p2p-impact-assessment

European Commission (2008): Towards Joint Programming In Research: Working together to tackle common challenges more effectively. COM(2008) 468 final. http://ec.europa.eu/research/press/2008/pdf/ com_2008_468_en.pdf

European Commission (2011): Recommendations Of The European Commission on the research joint programming initiative 'Urban Europe - global urban challenges, joint European solutions'. 2011/C 312/01. http://eur-lex.europa.eu/legal-content/EN/TXT/PDF/?uri=CELEX:32011H 1025(01)gfrom $=$ EN

European Commission (2012): Communication From The Commission To The European Parliament, The Council, The European Economic And Social Committee And The Committee Of The Regions: A Reinforced European Research Area Partnership for Excellence and Growth (2012) (COM(2012) 392 final) http://ec.europa.eu/research/era/pdf/era-communication/era-communication_en.pdf

Hunter, A.; Hernani, J. T.; Giry, C., Danielsen, K.; Antoniou, L. (2016): Evaluation of Joint Programming to Address Grand Societal Challenges Final Report of the Expert Group prepared by

European Commission (2020), Commission Staff Working Document Accompanying the document Communication from the Commission to the European Parliament, the Council, the European Economic and Social Committee and the Committee of the Regions A new ERA for Research and Innovation, SWD/2020/214 final. 
Georghiou, L. and Clarysse, B. (2006). Behavioural additionality of R\&D grants-introduction and synthesis. Government R\&D funding and company behaviour: measuring behavioural additionality, 9-38.

Ghosh, B. and Schot, J. (2019). Towards a novel regime change framework: Studying mobility transitions in public transport regimes in an Indian megacity. Energy Research and Social Science, 51(January), 82-95.

Gök, A., \& Edler, J. (2012). The use of behavioural additionality evaluation in innovation policy making. Research Evaluation, 21(4), 306-318.

High Level Group for Joint Programming (2014): Report of the GPC Working Group Measuring JPIs Progress and Impact. ERAC-GPC $1308 / 1 / 14$

High Level Group for Joint Programming (2016): Final Report of the GPC Implementation Group 3 "Monitoring and evaluating JPIs", ERACGPC 1310/16.

JPI Urban Europe (2015), Strategic Research and Innovation Agenda, https://jpi-urbaneurope.eu/app/uploads/2016/05/JPI-Urban-EuropeSRIA-Strategic-Research-and-Innovation-Agenda.pdf

JPI Urban Europe (2015): Strategic Research and Innovation Agenda: Transition Towards Sustainable and Liveable Urban Futures; http://jpiurbaneurope.eu/downloads/jpi-sria-def-pdf.

JPI Urban Europe (2019), Strategic Research and Innovation Agenda 2.0, https://jpi-urbaneurope.eu/app/uploads/2019/02/SRIA2.0.pdf

Kivima, P. (2020), Transformative Ryl policies, Key-note at the dialogue session for transformative R\&I policies, IST Conference 2020. Vienna.

Kivimaa, P., Hyysalo, S., Boon, W., Klerkx, L., Martiskainen, M., \& Schot, J. (2019). Passing the baton: How intermediaries advance sustainability transitions in different phases. Environmental Innovation and Societal Transitions, 31(July 2018), 110-125.

Kuhlmann, S., \& Rip, A. (2018). Next-generation innovation policy and grand challenges. Science and public policy, 45(4), 448-454.

Larosse, J. (2004). Conceptual and empirical challenges of evaluating the effectiveness of innovation policies with "Behavioural Additionality"(the case of IWT R\&D subsidies). IWT Flanders, Belgium.

Larrue, Ph. (2019), A new era for "mission-oriented" STI policies by Philippe Larrue, https://community.oecd.org/community/cstp/missionoriented-policies/blog/2019/06/17/a-new-era-for-mission-oriented-stipolicies-by-philippe-larrue-oecd-policy-analyst, OECD.

Larsen, H. (2019): Capabilities, Networks and Directionality. Innovation Policy for the Sustainable Development Goals, PHD thesis Imperial College, London.

Markard, J., Raven, R., \& Truffer, B. (2012). Sustainability transitions: An emerging field of research and its prospects. Research policy, 41(6), 955-967.
Mayne, J. (2008). Contribution analysis: An approach to exploring cause and effect (No. 563-2016-38893).

Mayne, J. (2011). Contribution analysis: Addressing cause and effect. Evaluating the complex, 53-96.

Mazzucato, M. (2019). Governing missions in the European Union. Independent Expert Report.

Meyer, S., Böhme, K., Dinges, M. (2017) Monitoring and Evaluation Concept of the Joint Programming Initiative Urban Europe, Vienna.

Meyer, S., Dinges, M. (2017), Toolbox of current and novel alignment modalities, https://www.era-learn.eu/documents/era-learn-publications/synthesis-report_alignment_sept2017_final.pdf

Molas-Gallart, J., Boni, A., Schot, J., Giachi, S. (2020). A formative approach to the evaluation of Transformative Innovation Policy; TIPC Working Paper, TIPCWP2020-01. Online access: http://www.tipconsortium. net/wp-content/uploads/2020/07/Paper-FORETIP-1.pdf

Schartinger, D., Rammer, C. and Fröhlich, J. (2006). Knowledge interactions between universities and industry in Austria: sectoral patterns and determinants. In Innovation, networks, and knowledge spillovers (pp. 135-166). Springer, Berlin, Heidelberg.

Schot, J. and Steinmueller, W. E. (2018). Three frames for innovation policy: R\&D, systems of innovation and transformative change. Research Policy, 47(9), 1554-1567.

Schot, J., Kivimaa, P.and Torrens, J. (2019). Transforming Experimentation: Experimental Policy Engagements and Their Transformative Outcomes. Transformative Innovation Policy Consortium: Brighton, UK.

SRU (Sachverständigenrat für Umweltfragen) (2016): Umweltgutachten 2016. Vorreiterpolitik für eine ökologische Transformation. Berlin.

SRU (Sachverständigenrat für Umweltfragen), (2015): 10 Thesen zur Zukunft der Kohle bis 2040. Berlin: SRU. Kommentar zur Umweltpolitik 14.

TAFTIE (2016), Future Competence Centre Programmes, Report of the TAFTIE Task Force on Competence Centre Programmes CompAct.

Von der Leyen, U. (2019), A Union that strives for more - My agenda for Europe, Political guidelines for the next European Commission. https:// ec.europa.eu/commission/sites/beta-political/files/political-guidelinesnext-commission_en.pdf.

Weber, K. M. and Rohracher, H. (2012). Legitimizing research, technology and innovation policies for transformative change: Combining insights from innovation systems and multi-level perspective in a comprehensive 'failures' framework. Research Policy, 41(6), 1037-1047.

Weber, M., Lamprecht, K. and Biegelbauer, P. (2019). The Shaping a new understanding of the impact of Horizon Europe: the roles of the European Commission and Member States. fteval Journal for Research and Technology Policy Evaluation, 47, 146-154. 


\section{AUTHORS}

\section{MICHAEL DINGES}

AlT - Austrian Institute of Technology

Giefinggasse 4, 1210 Vienna, Austria

E: michael.dinges@ait.ac.at

\section{SUSANNE MEYER}

AlT-Austrian Institute of Technology

E: susanne.meyer@ait.ac.at

\section{CHRISTOPH BRODNIK}

AlT - Austrian Institute of Technology

E: christoph.brodnik@ait.ac.at

Acknowledgements

This paper draws upon results by European Union's Horizon 2020 research and innovation programme under grant agreement 1) ID: 811171 , project ERA-LEARN and 2) ID: 726744 EXPAND - enhancing co-creation in JPI Urban Europe through widening Member State and stakeholder participation.

\section{KEYWORDS}

transformation, innovation policy, multi-level-perspective, monitoring systems, theory of change, European Partnerships 